\title{
NOTE ON THE TRANSLATION
}

W e have based this translation on the edition of the play in volume 5 of Li Yu quanji 李漁全集 (Hangzhou: Zhejiang guji, I99I), with reference to the annotations by Huo Xianjun and Zhang Guopei in Liweng chuanqi shizhong jiaozhu 笠翁傳奇十種校注 (Tianjin: Tianjin guji, 2008). Jing Shen also consulted the rare editions of Liweng shizhong $q u$ 笠翁十種曲 from the reign of the Kangxi emperor (I662-I722) in the collections at the National Library of China in Beijing and at National Taiwan University in Taipei. Both libraries have given us permission to use the illustrations from those two editions in this book. The translation was a collaboration, although the research behind the notes and the first draft of the translation were entirely the work of Jing Shen.

Readers can easily distinguish the three different components of the play text in translation-arias, verses, and prose dialogues - as shown by tune titles and stage directions. In an aria, extrametrical words are printed in a smaller font. The lines of arias are indented farthest and are introduced by the tune titles given in romanization and enclosed in parentheses. Recited lines are indented less far and, following the convention of the text, are not preceded by any stage direction. These 
lines may be parallel-prose couplets, comic doggerel, more formal shi poetry in lines of equal length, or ci poems (lyrics) written to matrices bearing the names of the tunes to which those poems were originally sung. Although the melodies had been lost for centuries by Li Yu's time, ci poems are conventionally identified with these lost tune titles, here enclosed in parentheses. 